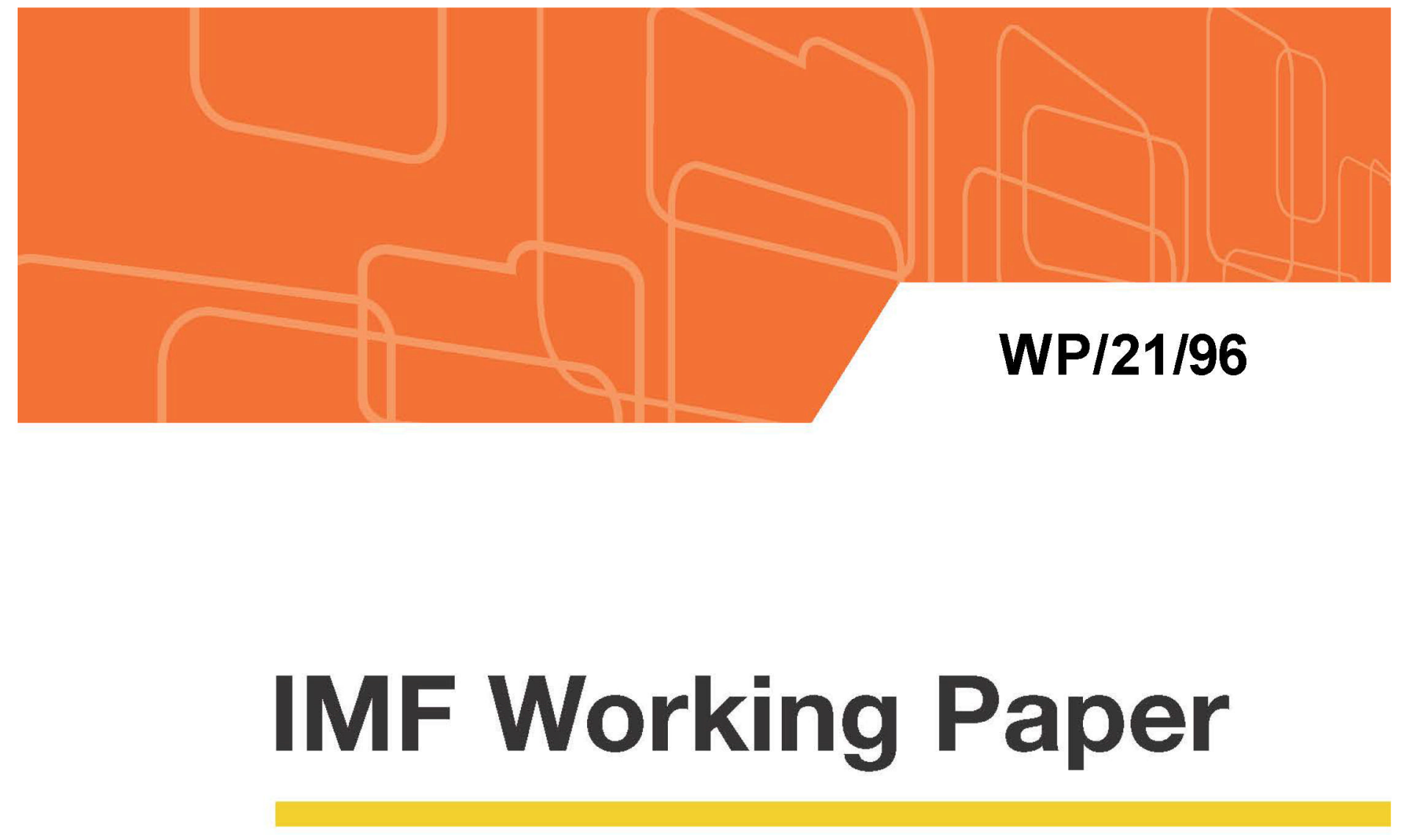

\title{
Enhancing Resilience to Climate Change in the Maldives
}

\author{
by Giovanni Melina and Marika Santoro
}

IMF Working Papers describe research in progress by the author(s) and are published to elicit comments and to encourage debate. The views expressed in IMF Working Papers are those of the author(s) and do not necessarily represent the views of the IMF, its Executive Board, or IMF management. 


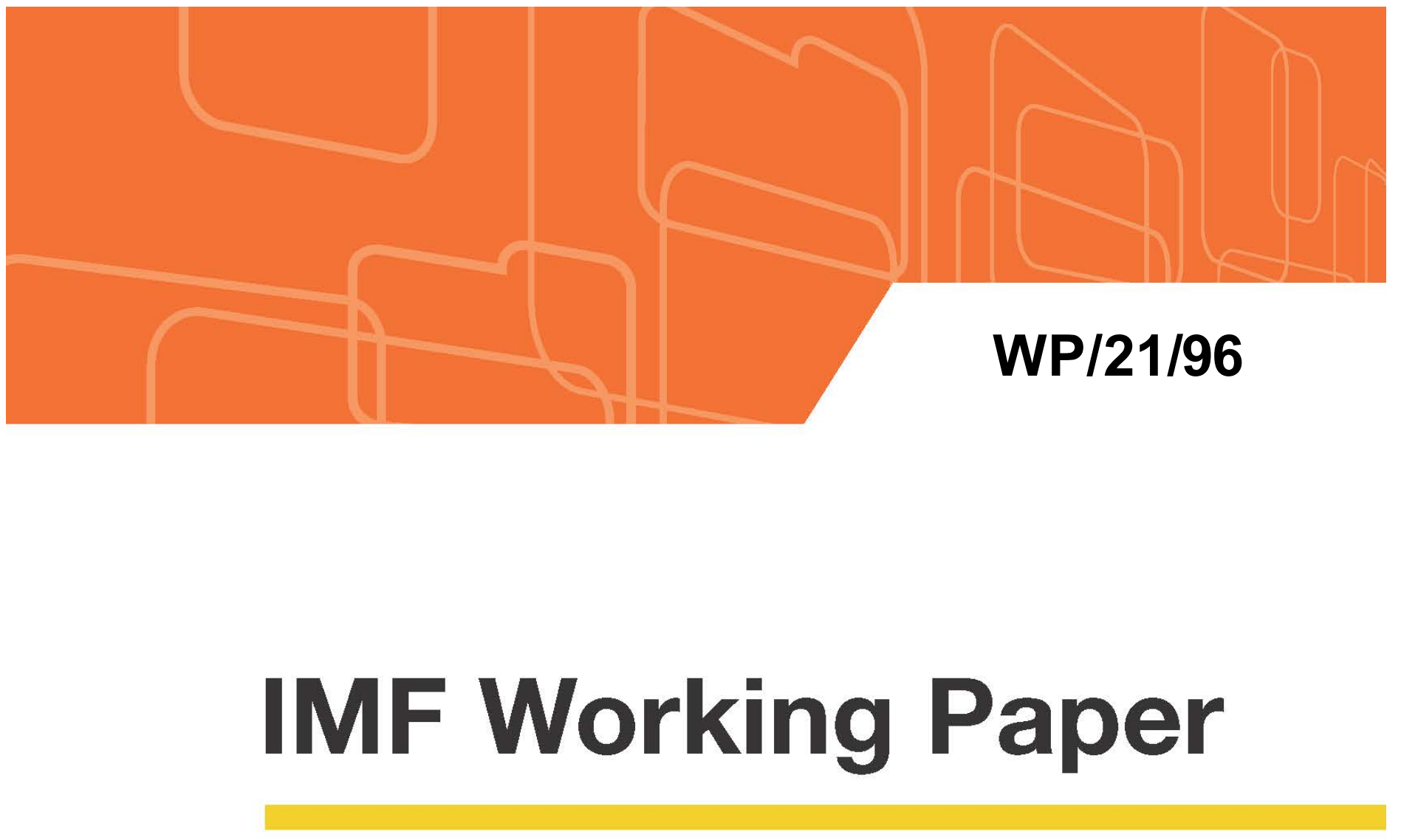

\title{
Enhancing Resilience to Climate Change in the Maldives
}

\author{
by Giovanni Melina and Marika Santoro
}

IMF Working Papers describe research in progress by the author(s) and are published to elicit comments and to encourage debate. The views expressed in IMF Working Papers are those of the author(s) and do not necessarily represent the views of the IMF, its Executive Board, or IMF management.

I N T E R N A T I O N A L M O N E T A R Y F U N D 
IMF Working Paper

Asia-Pacific and Research Department

\section{Enhancing Resilience to Climate Change in the Maldives ${ }^{1}$}

Prepared by Giovanni Melina and Marika Santoro

Authorized for distribution by Eugenio Cerutti and Chris Papageorgiou

April 2021

IMF Working Papers describe research in progress by the author(s) and a re published to elicit comments and to encourage debate. The views expressed in IMF Working Papers are those of the author(s) and do not necessarily represent the views of the IMF, its Executive Board, IMF management, or FCDO.

\section{Abstract}

The increased likelihood of adverse climate-change-related shocks calls for building resilient infrastructure in the Maldives. Fulfilling these infrastructure needs requires a comprehensive analysis of investment plans, including with respect to their degree of climate resilience, their impact on future economic prospects, and their funding costs and sources. This paper analyzes these challenges, through calibrating a general equilibrium model. The main finding is that there is a significant dividend associated with building resilient infrastructure. Under worsened climate conditions, the cumulative output gain from investing in more resilient technologies increases up to a factor of two. However, given the Maldives' limited fiscal space, particularly after COVID-19, the international community should also step up cooperation efforts. We also show that it is financially convenient for donors to help build resilience prior to the occurrence of a natural disasters rather than helping finance the reconstruction ex-post.

JEL Classification Numbers: Q54, Q58

Keywords: Climate change, natural disasters, public investment, adaptation infrastructure, Maldives.

Authors' E-Mail Address: GMelina@imf.org, MSantoro@imf.org

\footnotetext{
${ }^{1}$ This paper is part of a research project on macroeconomic policy in developing countries supported by the U.K's Foreign, Commonwealth and Development Office (FCDO). We are gra teful to Eugenio Cerutti for very useful comments and suggestions. All remaining errors a re ours.
} 


\section{Contents}

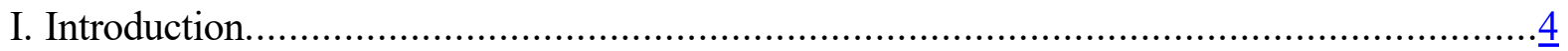

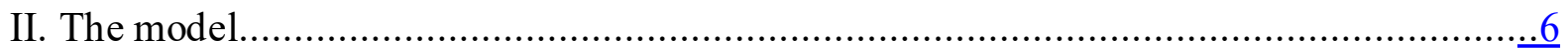

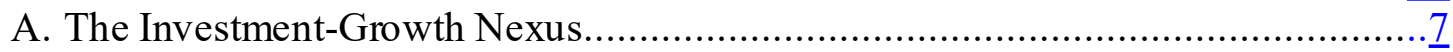

B. The Fiscal Adjustment..........................................................................

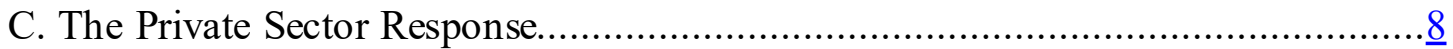

D. Building Resilience to Natural Disasters.....................................................

E. Capturing the Maldivian Context .................................................................

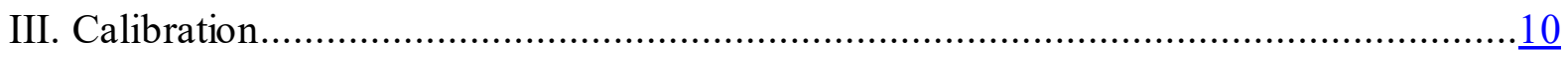

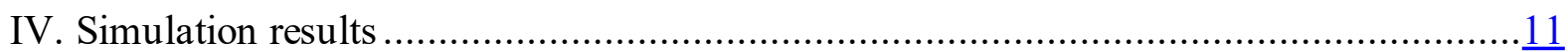

A. Illustrative experiments with a one-off disaster shock.....................................12

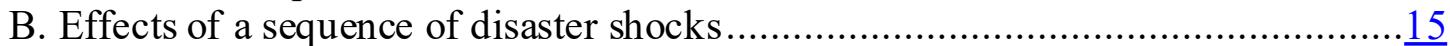

C. The gains from adaptation under worsened climate conditions.............................16

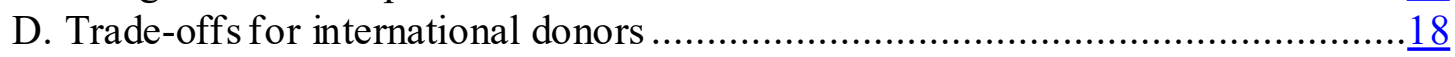

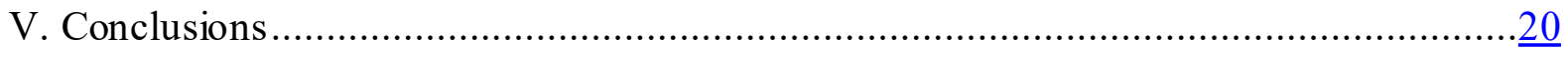




\section{INTRODUCTION}

Risks related to climate change are increasing across the world, especially in South Asia. As of today, the Maldives have been relatively less affected by climate-changed-related natural disaster than other countries in the region, but the likelihood of more impactful events is growing, especially with rising sea levels (Agarwal et al 2021, IMF 2020).

The Maldives will be particularly vulnerable to the consequences of climate change, given that the larger quantum of precipitations will worsen the potential for damages from coastal flooding during storms, in a context of rising sea levels and enhanced salinization (IPCC 2018). Vulnerabilities are aggravated by a general infrastructure gap in the country. ${ }^{2}$ While continuing to boost infrastructure investment is needed to achieve further economic development, the increased likelihood of adverse climate-related shocks calls for building weather resilient infrastructure. Fulfilling these needs requires a comprehensive analysis of investment plans, their impact on future economic prospects, as well as the financing strategy, especially in the presence of limited fiscal space after the COVID-19 shock.

In this paper, we employ a model, the Debt-Investment-Growth (DIG) of Buffie and others (2012), extended as in Marto, Papageorgiou, and Klyuev (2017) to make it suitable for small economies prone to natural disasters (DIGNAD), and calibrate it to the case of the Maldives. The DIGNAD model provides a framework to evaluate macroeconomic and financial implications of alternative investment programs and financing strategies. The production in the economy is carried out by firms in the tradable (e.g., especially the tourism sector in the case of the Maldives) and non-tradable sectors, using private and public capital, besides labor. In the model, a natural disaster shock affects the economy by mainly destroying capital and reducing total factor productivity (TFP). Public capital can be of two different types, based on how resilient it is to weather-related events: standard and adaptation capital. ${ }^{3}$ Adaptation capital is characterized by a lower depreciation rate than standard infrastructure to capture higher durability.

We use the model to perform a series of stylized experiments and quantify the benefits of enhancing climate-change resilience in the Maldives. We show that there is a dividend associated with building infrastructure using adaptation technologies. The initial cost of this type of infrastructure is usually elevated when compared to standard structures. However, when hit by a natural disaster shock, adaptation capital withstands adverse conditions reporting less damages, consequently cutting GDP losses by more than half. This is in essence the dividend associated with adaptation infrastructure. Our exercise highlights that financial resources required during reconstruction phases in case of damages to standard capital are more elevated and pose issues of sustainability because, given the country has

\footnotetext{
${ }^{2}$ Physicalinfrastructure needs in South Asia are well documented, even regardless of the need for climatechange-resilient infrastructure. For example, Rozenberg a nd Fay (2019) estimate that South Asia has the highest a daptation deficit in coastal protection. More generally, they estimate that, in order to a chieve their development goa ls, low- and middle-income countries will need to spend between 2 and 8 percent of GDP a nnually until 2030.

${ }^{3}$ Relative to standard infrastructure, adaptation infrastructure could be complementary-e.g., sea walls, breakwater retrofitting or climate proofing — or substitute-e.g., clima te resilient infrastructure.
} 
very limited fiscal space to use deficit financing, they would require an unfeasible increase in tax pressure or cuts in non-infrastructure spending.

Small island economies like the Maldives are often afflicted by adverse natural disaster shocks repeatedly, without being able to fully return to the initial level of productive capital and TFP. In other words, the effects of sequences of shocks accumulate over time weighing permanently on macroeconomic outcomes (as recently shown by Cantelmo, Melina and Papageorgiou, 2019). We therefore explore also the case of sequential natural disaster occurrence, that is, shocks of an historic average size for the Maldives that hit the economy every year. We find that, in the long run, the cumulated output loss suffered by the economy under the adaptation capital scenario is less than half the loss suffered under the standard capital scenario.

In South Asia, rainfalls are expected to increase by 10-20 percent by the end of the 21 st century (IPCC, 2018). Natural disaster damages are therefore expected to become more severe going forward, with increased precipitations compounded by sea level rise. Under worsened climate conditions, captured by an increase in the shock size, the cumulative output gain from investing in adaptation increases up to a factor of two. In other words, investing in adaptation infrastructure makes even greater economic sense because it reduces the extent of even larger damages.

Given the high fiscal costs associated with a strategy of building infrastructure more resilient to worsening climate conditions, the international community will likely have to step up cooperation efforts. In helping small economies build resilience to natural disasters, donors face a key trade-off. They can contribute to the initial investment phase, helping secure a more expensive adaptation capital, which will deliver lower losses in the aftermath of a disaster shock, or wait for a disaster shock to occur, facing more elevated costs associated with standard infrastructure. We find that, over a ten-year horizon, the cumulated discounted fiscal savings deriving from the smaller damages associated to adaptation infrastructure are more than double the size of the extra spending required to build it, broadly in line with averages for disaster-prone developing countries (Cantelmo, Melina and Papageorgiou, 2019). In other words, the lower expected spending in the aftermath of a disaster shock associated with resilient infrastructure, in net present value, more than offsets the initial higher resources required in the construction phase.

This paper relates to two strands of the literature. It relates to previous research on the debt sustainability concerns that arise with alternative public investment programs. Earlier work in this field exploits a similar framework to ours and quantifies growth benefits of public investment (Barro, 1990; Barro and Sala-i-Martin, 1992) while later work focuses more on debt sustainability issues (Buffie et al., 2012). While our framework builds on some of that previous research, our focus is more on illustrating and analyzing key tradeoffs in infrastructure investment and financing decisions once climate change is brought into the picture.

Our paper also contributes to the flourishing literature on the impact of natural disasters on economic performance, investment decisions and debt sustainability in small economies 
(Cavallo and Noy, 2011; Noy, 2009; Bevan and Cook, 2015; Marto, Papageorgiou, and Klyuev, 2017; Cantelmo, Melina and Papageorgiou, 2019). Other papers in this same strand have looked at what are the country characteristics that influence the impact of climate change on the economy and found that the level of income, financial access, trade openness, and democratic institutions are key for the recovery after a disaster shock and are associated with fewer causalities (Felbermayr and Gröschl, 2014).

In the same spirit of Cantelmo, Melina and Papageorgiou (2019), our work extends the findings of the literature on natural disasters in small economies in the direction of examining not only the tradeoffs between investment in more costly adaptation infrastructure and disaster damages, but also the key role of foreign aid. We calculate the financial needs during the post-disaster phase and find that they could be very elevated, raising questions about the capabilities of small economies to withstand the effects using only available domestic fiscal measures, especially in the absence of fiscal space. Given the importance of donor funds, we extend our contribution to the analysis of costs and benefits associated with investing in adaptation infrastructure in small economies from the perspective of international donors.

The remainder of the paper is organized as follows. Section II describes the basic features of the model and Section III presents the data used for its calibration. Section IV presents illustrative experiment to highlight the macroeconomic impact of the natural disaster and the role of adaptation infrastructure, and then illustrates two extensions of the analysis: the consideration of more frequent climate related shocks; and implications for donors. The conclusions are presented in Section V.

\section{THE MODEL}

This paper uses the DIGNAD model by Marto, Papageorgiou, and Klyuev (2017), which in turn extends the DIG model of Buffie and others (2012) to simulate the impact of Cyclone Pam on Vanuatu in 2015. ${ }^{4}$ The DIG model was developed to study macroeconomic impact of public investment for low-income and small open economies. It is a general equilibrium growth model which provides a framework for thinking through scaling up public investment and its debt implications. DIG is a real, dynamic, two-sector small open economy model with traded and non-traded goods sectors. In each sector, public capital is used as an input of production by perfectly competitive firms, jointly with private capital and labor. The government has access to external and domestic debt while fiscal instruments ensure debt sustainability. In other words, the model puts together several crucial pieces that help capture the main mechanisms and policy issues of interest for debt sustainability analysis, particularly those associated with the linkages between public investment, growth, and debt. These crucial pieces comprise (i) the investment-growth nexus, (ii) the fiscal adjustment, and (iii) the private sector response. We proceed to elaborate on these pieces, on how the DIGNAD extension incorporates crucial features related to natural disasters and adaptation, and how it can be applied to the Maldivian context.

\footnotetext{
${ }^{4}$ Here we outlay the key features of the model, while referring the rea der to the original pa per for a detailed description.
} 


\section{A. The Investment-Growth Nexus}

To capture the investment-growth nexus, the model incorporates a neoclassical production function, which uses labor, and private and public capital in each sector, as productive inputs. The technologies are assumed to be of the Cobb-Douglas type such as

$$
y_{t}=A_{t}\left(k_{t}^{g}\right)^{\psi}\left(k_{t}\right)^{\alpha}\left(l_{t}\right)^{1-\alpha},
$$

where $y_{t}$ is output, $A_{t}$ is total factor productivity, $k_{t}^{g}$ is public capital, $k_{t}$ is private capital, and $l_{t}$ is labor. The parameter $\psi$ of the production function determines the rate of return to installed public capital. Because public capital is productive, government spending can raise output directly and crowd in private investment. More specifically, public investment increases can translate into more public capital, which in turn raises the marginal productivity for private capital (and labor) and, through this channel, stimulates private investment.

\section{B. The Fiscal Adjustment}

The model considers different government financing options and states explicitly the fiscal policy reactions for different tax (and transfer) instruments that attempt to ensure debt sustainability. As in other dynamic models that ensure consistency between stock and flows, the budget constraint of the government plays a central role:

$$
\begin{gathered}
\underbrace{s_{t} \Delta a_{t}+s_{t} \Delta d_{t}+\Delta b_{t}}_{\text {Borrowing }}=\underbrace{s_{t} r_{a, t-1} a_{t-1}+s_{t-1} r_{d,-1} d_{t-1}+r_{t-1} b_{t-1}}_{\begin{array}{c}
\text { Interest } \\
\text { Payments }
\end{array}} \\
+\underbrace{i_{t}^{g}+g_{t}}_{\text {Spending }}-\underbrace{\mathcal{A}_{t}}_{\text {Grants }}-\underbrace{\mathcal{R}_{t}}_{\begin{array}{c}
\mathcal{R}_{t} \\
\text { other } \\
\text { Reverues }
\end{array}}-\underbrace{\sum_{j=1}^{m} \tau_{j t} n_{j t}}_{\text {Taxes }},
\end{gathered}
$$

where $s_{t}$ is the real exchange rate; $\Delta a_{t}, \Delta d_{t}$, and $\Delta b_{t}$ are external commercial, external concessional, and domestic borrowing, respectively, with their corresponding real interest rates $r_{a, t}, r_{d, t}$, and $r_{t}$; government spending corresponds to public investment $i_{t}^{g}$ and transfers/consumption spending $g_{t}$; revenues comprise grants $\mathcal{A}_{t}$, royalties from natural resources $\mathcal{R}_{t}$, and taxes on consumption and/or factor incomes, which are represented in a general form as $\tau_{j t} n_{j t}$ where $\tau_{j t}$ is the tax rate, and $n_{j t}$ represents consumption or any income from productive factors.

The fiscal analysis takes available grants and concessional borrowing as exogenously given. When this borrowing is not enough to cover the public investment scaling-up plan, a fiscal gap arises. Scenarios can be built also allowing external commercial and domestic borrowing help finance the public investment surge, with taxes and transfers responding to stabilize debt levels over time. Absent any additional financing sources, the government adjusts taxes and transfers to close the gap. 
While the path of public investment is set exogenously by the user to produce alternative policy scenarios, the model incorporates fiscal rules for tax instruments (and transfers), while allowing for the imposition of feasibility constraints on the pace or level of these fiscal adjustments. In general terms, the tax instruments $\tau_{j t}$ follow the non-linear fiscal rule

$$
\tau_{j t}=\operatorname{Min}\left\{\tau_{j}^{u}, \tau_{j t}^{r}\right\}
$$

where is $\tau_{j}^{u}$ is an exogenously imposed ceiling on tax (j) adjustment, reflecting policy feasibility constraints, and

$$
\tau_{j t}^{r}=\tau_{j t-1}+\lambda_{\tau}\left(\tau_{j t}^{\text {target }}-\tau_{j t-1}\right)+\lambda_{x}\left(x_{t}-x_{t}^{\text {target }}\right),
$$

with $\lambda_{\tau}, \lambda_{x}>0$, and where $\tau_{j t}^{\text {target }}$ is the debt-stabilizing value for the tax instrument, $x_{t}$ is the debt-to-GDP ratio-it could be domestic and/or external commercial-, and $x_{t}^{\text {target }}$ is an exogenously given debt target. Similar rules apply to current expenditures or transfers with the imposition of floors. Particularly the presence of these thresholds makes resorting to nonlinear solution methods a necessity.

\section{The Private Sector Response}

Being a general equilibrium model, the framework also incorporates the private sector response to policy actions. This is mostly related to private investment in both sectors and to private consumption. Investment is subject to real frictions such as adjustment costs. There is also limited access to international capital markets to capture financial market imperfections, and some heterogeneity regarding private consumption behavior. There are consumers who can smooth consumption because they have access to assets such as bonds and capital. There are also hand-to-mouth consumers who are forced to consume their income in every period. The households' modeling framework closely follow Marto et al. (2018, Section 2.3, p. 578). The presence of these consumers and distortionary taxes help break the so-called Ricardian equivalence.

The response of the private sector to increases in public investment and to fiscal adjustment can be summarized in the associated crowding in and crowding out effects. With a public investment scaling up, more public capital is accumulated. This raises the marginal product of capital, inducing more private investment and therefore crowding in. On the other hand, when the government uses domestic financing resources to invest, these resources are not available for private investment and consumption. Tax increases or transfers reductions lower private consumption. Hence fiscal policy can also crowd out private investment and consumption. Which effects dominates - crowding in versus crowding out - depends on several factors, such as the net rate of return of the installed capital. In the long run, there is always crowding in, if the projects are good. In the transition, crowding out may dominate, especially early on and if there is not enough foreign financing. 


\section{Building Resilience to Natural Disasters}

DIGNAD captures the challenges of closing infrastructure gaps in countries that frequently face natural disasters. The model has two forms of public capital: standard and adaptation infrastructure. ${ }^{5}$ Relative to standard infrastructure, adaptation infrastructure could be complementary - e.g., seawalls, breakwater retrofitting or climate proofing — or substitutee.g., climate resilient infrastructure. Adaptation infrastructure is characterized by greater durability and greater resilience, in that it suffers smaller damages in the aftermath of disaster shocks. Because of climate-proofing, which allows a more intensive use even under adverse weather conditions, adaptation capital also delivers a larger rate of return. Investing in resilience can raise the marginal product of private capital, crowding in private investment, while helping withstand the impact of natural disasters. In the event of a disaster, reconstruction efforts could then tap into traditional debt instruments-domestic, concessional, and external commercial — and/or donor grants. They would also require fiscal adjustment in the form of taxes and/or transfers, to stabilize debt ratios. Natural disasters could affect the economy through the following five effects/channels: (i) damages to private capital; (ii) damages to public capital; (iii) a temporary productivity loss; (iv) a decline in public investment efficiency during reconstruction; and (v) a loss in credit worthiness.

\section{E. Capturing the Maldivian Context}

The model serves as a framework for thinking about investment and financing in the Maldivian economy. While the tradable sector captures tourism, the non-tradable sector captures the rest of the economy. The limited fiscal space poses a challenge to large investment scale-ups, especially in the case of more costly adaptation infrastructure. This is especially the case after the COVID-19 shock, which had a huge impact on the Maldives' tourism dependent economy. The collapse in tourism government revenues and the large about 30 percent contraction in GDP led to a further increase in debt levels. The total publicly guaranteed debt level jumped from 78 percent of GDP at the end of 2019 to about 138 percent of GDP at end-2020Q3. This associated limited fiscal space could constrain infrastructure spending, especially on climate-change resilient technologies, unless the government increases revenue or taps donor funds (in the form of grants or concessional debt). On this point, different experiments illustrate infrastructure spending trade-offs in the remainder of the paper. We set up experiments along two main dimensions - investment options and financing - designed to prevent the accumulation of additional government debt.

\footnotetext{
${ }^{5}$ In line with Marto, Klyuev and Papageorgiou (2018), we assume an infinite intratemporal ela sticity of substitution between standard and adaptation infrastructure and, for both types of investment, an efficiency of 60 percent, mirroring IMF Public Investment Management Assessments for small developing countries.
} 


\section{Calibration}

The model is calibrated to the Maldivian economy with initial values set according to the data. ${ }^{6}$ Table 1 reports selected initial values and parameters calibrated at an annual frequency. The model is set to match historical averages given the need to capture steady state regularities in the data, rather than data related to cyclical or extreme shocks, such as COVID-19.

Steady-state public standard investment infrastructure as a share of GDP $\left(i_{z i, o}\right)$ is set at 11.9 percent, in accordance with historical data from the January 2020 IMF World Economic Outlook (WEO) database - pre COVID-19 shock. Given the small size of the economy, the calibration takes into account that a large share of output is produced using imports (imports are about 70 percent of GDP). In line with the average for small developing countries, we set the ratio of financially constrained consumers to 15 percent (Marto et al. 2018), which is also broadly in line with recent Maldivian data on the share of population with no deposit accounts at major banks. ${ }^{7}$

We use IMF and country authorities' debt data to set the initial values of public domestic, $b_{o}$, external commercial, $d_{o}$, and concessional debt, $d_{c, o}$, which amounted to 55 percent of GDP in 2019 cumulatively. ${ }^{8}$ While the real interest rate on concessional debt is essentially zero, the real interest rates on domestic and commercial debt were 9.3 and 2.5 percent, respectively. The tax rate on consumption is set at 6 percent, in line with the general goods and services tax, and the annual trend growth rate of the Maldives is set at 5 percent, according to historical economic performance.

Adaptation capital better withstands natural disasters than standard infrastructure. The former depreciates at a lower annual rate than the latter, i.e. $\delta_{z a}=0.03$ while $\delta_{z i}=0.075$, implying an additional lifespan for adaptation infrastructure of about 75 years as in Marto, Papageorgiou, and Klyuev (2017). Other parameters that determine the impact of natural disasters are either in line with Marto, Papageorgiou, and Klyuev (2017) or IMF (2017). For example, as far as the return on standard infrastructure is concerned, we set a value of 25 percent at the initial steady state. The gross return on adaptation infrastructure is set at a value twice as large, because climate-proofing of public capital extends its average usage

\footnotetext{
${ }^{6}$ In the absence of specific information, we used the parameters of the average LIC in the DIG model, most of which were also used in calibrating the DIGNAD model of Marto, Papageorgiou, and Klyuev (2017).

${ }^{7}$ The share of population with an account at Bank of Maldives was 82 percent in 2016. See report on financial inclusion by the Maldives Monetary Authority: http://www.mma.gov.mv/documents/Annual\%20Report/2016/financial-Inclusion\%20(English).pdf.
}

${ }^{8} \mathrm{~A}$ large part of the debt from state-owned enterprises (SOEs) is gua ranteed by the central government. The sum of public and publicly guaranteed debt is about 77 percent of GDP at end-2019. In the model, for simplifica tion purposes, we do not take into account SOE debt, but its inclusion would not materially change the conclusions given the already limited fiscal space of the central government. 
even under adverse weather conditions. ${ }^{9}$ Several other parameters determine the government's desired speed of infrastructure reconstruction. We choose values such that the stock of public and private capital, on average, return to pre-disaster levels in 10 years, in the case of standard infrastructure financed by taxes.

Table 1: Selected initial values (in percent) and calibrated parameters

\begin{tabular}{|c|c|c|}
\hline Definition & Parameter & Value \\
\hline \multicolumn{3}{|l|}{ Initial values } \\
\hline $\begin{array}{l}\text { Public standard investment to GDP } \\
\text { Public a daptation investment to GDP } \\
\text { Public domestic debt to GDP } \\
\text { Public concessional debt to GDP } \\
\text { Public external (commercial) debt to GDP } \\
\text { Real interest rate on public domestic debt } \\
\text { Real interest ra te on public concessional debt } \\
\text { Real interest ra te on public externaldebt } \\
\text { Disa ster fund sa vings to GDP } \\
\text { Consumption tax (VAT) rate } \\
\text { Priva te external debt to GDP }\end{array}$ & $\begin{array}{c}i_{z i, o} \\
i_{z a, o} \\
b_{o} \\
d_{o} \\
d_{c, o} \\
r_{o} \\
r_{d, o} \\
r_{d c, o} \\
\mathfrak{s}_{o} \\
\tau_{o}^{c} \\
b_{o}^{*}\end{array}$ & $\begin{array}{c}11.9 \\
0.0 \\
37.5 \\
5.7 \\
12.0 \\
9.3 \\
0.0 \\
2.5 \\
0.0 \\
6.0 \\
12.3\end{array}$ \\
\hline \multicolumn{3}{|l|}{ Calibrated parameters } \\
\hline $\begin{array}{l}\text { Depreciation rate of standard public infrastructure }(\%) \\
\text { Depreciation rate of a daptation public infrastructure }(\%) \\
\text { Depreciation rate of private capital }(\%) \\
\text { Trend percapita growth rate }(\%)\end{array}$ & $\begin{array}{c}\delta_{z i} \\
\delta_{z a} \\
\delta_{k} \\
G\end{array}$ & $\begin{array}{l}7.5 \\
3.0 \\
5.0 \\
5.0\end{array}$ \\
\hline
\end{tabular}

\section{Simulation Results}

In this section, we set up scenarios in which the authorities invest in public infrastructure projects and then a natural disaster shock occurs. All the experiments show the interaction of the policy options with the impact of a typical climate-related shock on macroeconomic outcomes. After describing the main experiments, we analyze the response of selected macroeconomic variables to the disaster shocks. Next, we analyze the impact of worsened climate conditions and, finally, we examine important trade-offs between pre-disaster and post-disaster financial interventions from the donors' perspective.

\footnotetext{
${ }^{9}$ The ma cro-based estimates in Da lga ard and Hansen (2005) ra nge between 15 and 30 percent for a wide array of different estimators. Some micro estimates from Foster a nd Briceno-Garmendia (2010) suggest returns for electricity, wa ter and sa nitation, irriga tion, and roads ranging between 17 and 24 percent. Other studies find even larger returns, beyond 50 percent, for some investment categories (Canning and Bennathan, 1999).
} 


\section{A. Illustrative experiments with a one-off disaster shock}

The financing strategy is crucial in the case of the Maldives, given its limited fiscal space. To this aim, illustrative experiments are set up along two main dimensions: investment options (adaptation versus standard infrastructure) and financing. For the sake of simplicity, the assumption is that there is no adaptation infrastructure in the initial steady state, and that authorities use the same budget envelope of 1 percent of GDP for 5 consecutive years to build standard or adaptation infrastructure. A natural disaster occurs as soon as this investment plan is completed. Assuming the same budget envelop for the two types of investment allows comparing the benefits associated with each taxpayer's dollar spent. Section IV.D takes the additional cost of adaptation infrastructure into account to evaluate important tradeoffs.

The experiments help address three main questions: (i) What are the gains associated with adaptation infrastructure in the face of a natural disaster? (ii) How does the outcome change when the government finances the initial investment with international grants, rather than by raising taxes? (iii) What are the financing needs for reconstruction in the aftermath of a disaster, depending on whether the government has invested on standard or adaptation capital? And what does this mean for international donors?

We consider three scenarios: (1) investment in standard infrastructure; (2) investment in adaptation infrastructure financed by higher taxation; and alternatively (3) investment in adaptation infrastructure financed by international grants. These simulations, for simplicity, assume that the post-disaster reconstruction is financed by increased taxation, under the assumption that the Maldives has no fiscal space for deficit-financed spending. Given the public investment needs (pre and post disaster), the model calculates endogenously the amount of taxes necessary to keep the budget balanced, with no need for new debt issuance. The natural disaster shock is assumed to destroy 10 percent of both private and public capital and to trigger a symmetric productivity drop in both the tradable and non-tradable sectors. While the magnitude of this shock is illustrative, it is in the range of shocks similar to highly disruptive floods observed in island countries. ${ }^{10}$

Figure 1 shows the impulse responses of selected macroeconomic variables during an accumulation phase, characterized by investment in either standard or adaptation infrastructure, and to a one-off natural disaster shock in the Maldives. The shock occurs during the fifth year after the investment phase started. All responses are in percentage or percentage point deviations from the initial steady state.

Investing in adaptation capital yields a dividend even before the natural disaster occurs. During the first phase, when the government is stepping up infrastructure investment, real GDP and private investment increase. Investing in adaptation raises the marginal product of private capital more than in the case of standard infrastructure, crowding in a larger fraction

\footnotetext{
${ }^{10}$ In the experiments, the choice of invest ing only in sta ndard or a daptation infrastructure is motivated by the objective of illustrating the properties a ssociated with the two types of infrastructure in a clear-cutway. Indeed, the a uthorities could in practice opt for a combination of investment types.
} 
of private investment prior to the disaster. The higher (net) marginal return on investment is determined by the superior durability of resilient infrastructure, captured by a lower depreciation rate relative to that of standard infrastructure, and its higher gross return (see Section III).

Figure 1: Impact of a stylized disaster shock on selected macroeconomic variables

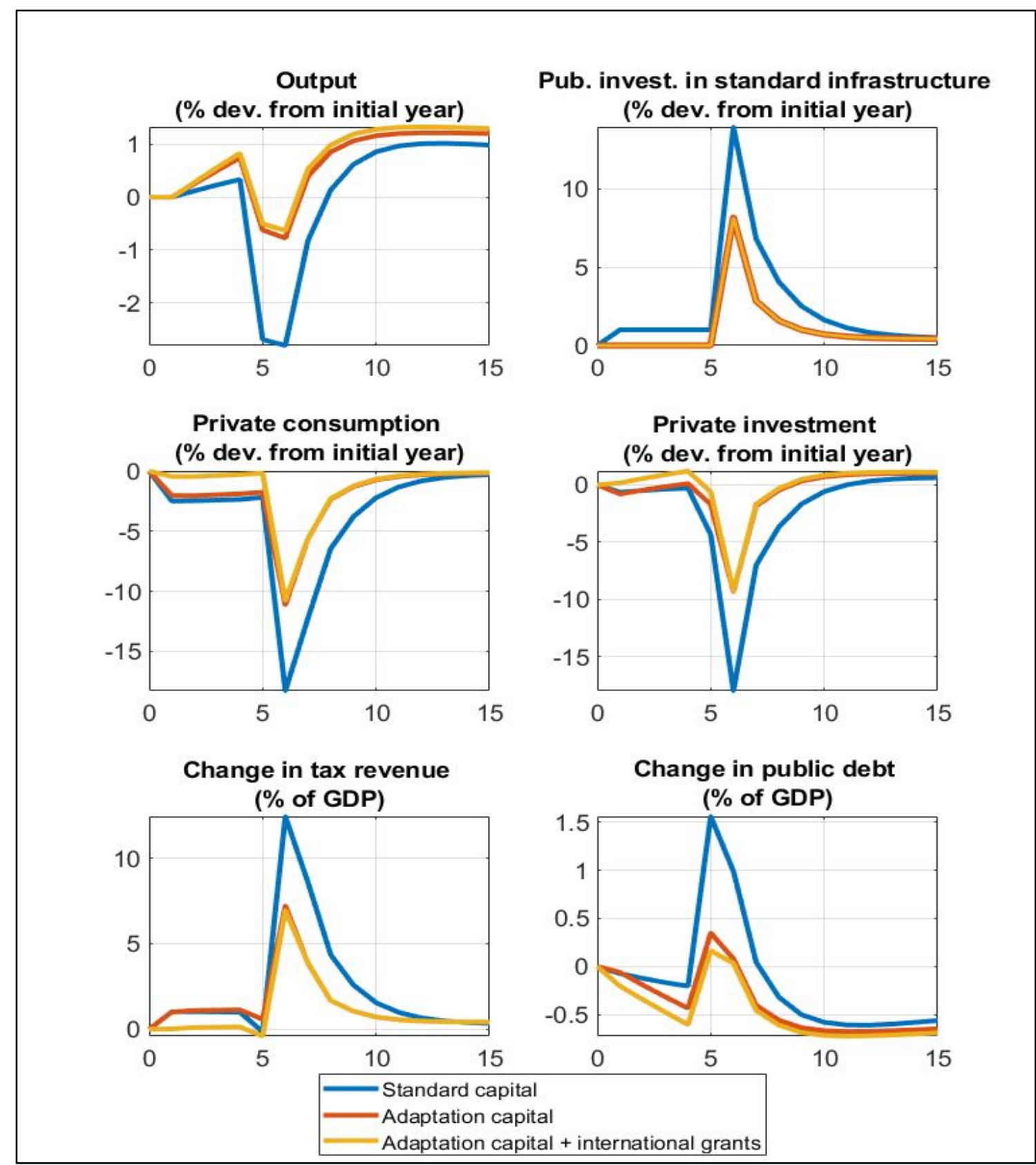

Adaptation infrastructure displays even larger benefits in the post-disaster phase. In response to a natural disaster that destroys 10 percent of capital in all sectors, GDP declines about 1.2 percent in the case of adaptation infrastructure capital and about 3 percent in case of standard infrastructure. Consumption and private investment both fall initially by about 15 percent while public investment spikes up to replace the lost capital, driving the recovery. In the 
aggregates, total investment falls only marginally on impact as public effort steps up. The model captures the complementarities between standard and adaptation infrastructure, as public investment in standard capital can be partly intertwined with adaptation capital therefore requiring its increase in the post-reconstruction phase, as shown in the top-right chart. This helps portraying adaptation capital as reinforcing the quality of standard capital not just as a strict alternative, for instance in the case of climate-proofing roads that can withstand stronger natural disasters. It is worth stressing that, primarily due to nonlinearities in the model, gains from adaptation infrastructure in the aftermath of disaster shocks depends on the shock size and on initial conditions, such as the magnitude and duration of ex-ante investment. Also, private investment in the tradable sector during post-disaster phases leads in speed non-tradable investment. The figure highlights persistent effects of a natural disaster on the economy, which takes about three-four years to fully recover.

Public debt to GDP increases by 1 percentage point more in the case of damages to standard capital. The worsening of the public financial position relative to GDP is a direct effect of the denominator falling since the numerator is by assumption remaining constant at the steady state level, thanks to the increase in the tax revenue to finance the reconstruction. If the economy has only standard public infrastructure, the tax pressure would have to be twice as large (6-7 additional percentage points of GDP) than the case in which damages are less severe thanks to capital built to withstand disaster shocks. ${ }^{11}$ Consequently, consumption of both Ricardian and non-Ricardian households will suffer a larger hit especially in the short run, mostly due to a lower disposable income.

It is worth remembering that the model's initial steady state is calibrated using historical averages of Maldivian data. As discussed, the COVID-19 pandemic increased public debt to a level well above its historical average. If a natural disaster of the same size were to occur at a time when the debt-to-GDP ratio is already high to begin with, the model predicts that the dynamic response of GDP and other key variables would be virtually unaltered. However, even maintaining the balanced budget assumption and the same dynamic response of GDP, the percent point change in the debt-to-GDP ratio would be larger purely due to the higher initial debt level. This would constrain further the fiscal space. ${ }^{12}$

These are some key benefits of adaptation infrastructure. Thanks to that type of investment, the magnitude of the natural disaster damages to public and private infrastructure, as well as on sectoral TFP is reduced. This can more than halve the losses in terms of GDP at the trough triggered by the natural disaster. The tax pressure required for the reconstruction in case of standard infrastructure would lead to a (politically) unfeasible increase in revenues in the aftermath of the shock and would be at odds with the authorities' goal to smooth the impact on households' consumption. The large increase in tax revenue required to support the reconstruction underscores the large financing gaps that authorities could face with

\footnotetext{
${ }^{11}$ If the burden were to fall only on consumption taxes, the government would have to raise the average tax ra te by about 18 percentage points in the short term - which would be unrealistic - and by about 2 percentage points over the medium term.

${ }^{12}$ Additional simulation results, where the initial level of debt-to-GDP wa s calibrated to be higher, are availa ble from the authors upon request.
} 
worsening climate conditions. Grant-financing can reduce pre- and post-disaster cost or eliminate it if it covers the investment plan in full, as in Figure 1. The figure also highlights how tax financed investment in both standard and adaptation infrastructure would also lead to a sacrifice in terms of GDP, private consumption and investment also in the pre-disaster period, when public investment is ramping up. These results are robust within a reasonable range of values for relevant parameters, such as the intertemporal discount rate, capital depreciation rates and the parameters governing the resilience of infrastructure to natural disaster shocks.

\section{B. Effects of a sequence of disaster shocks}

It is worth stressing that the exercise in the previous section considers only a one-off event of average intensity. Given that many disaster-prone countries are projected to experience natural disasters more frequently, they are less likely to fully recover from a disaster shock before another shock occurs. The effects of sequences of shocks accumulate over time weighing permanently on macroeconomic outcomes (as recently shown by Cantelmo, Melina and Papageorgiou, 2019).

To this aim, the model can also be used to realistically simulate a sequence of yearly shocks that in the case of the Maldives are meant to capture the damages occurring periodically due to floods. Due to heavy precipitations, usually occurring in the summertime, and increased salinization of the ground related to the sea level rise, the Maldives are afflicted about every year by consistent periods of inundation. Given the uncertainty of the total economic cost associated with climate-related shocks, we avoid the direct approach of estimating a correct damage function related to a specific natural disaster. On the contrary, we calibrate the damage function such that the damage is a certain percent of the GDP. The latter is taken from estimates of average damages in terms of GDP in the literature (Bayoumi et al., 2020). Based on estimates by Bayoumi et al. (2020), we can place the average economic damages from floods in a small sub-tropical economy in the neighborhood of 0.3 percent of GDP (yearly). Using the model, we then calculate the dividend deriving from adaptation infrastructure, given the existing estimates of its ability to withstand adverse shocks and the associated lower GDP losses, as shown in Figure 1.

Figure 2 displays the cumulative impulse reaction functions for an economy calibrated to the fundamentals of the Maldives. Importantly, here in year zero the investment scale-up program (in standard or adaptation capital) has been completed and, in year 1, the sequence of shocks begins. Both the blue and the red line plot the effects of recursive natural disaster shocks which deliver damages of 0.3 percent on impact (yearly) in terms of GDP losses, in the standard capital scenario. The cumulative economic impact of yearly shocks is calculated considering overlapping impacts of sequential shocks, which occur while the economy is on a transition path. All percentage deviations are calculated relative to a baseline scenario without natural disaster shocks.

In the case of standard capital (blue line), real GDP would be about 1 percent lower after 10 years if the economy were hit annually by a sequence of disasters of size similar to those experienced by the Maldives. Under the hypothesis that the infrastructure is resilient (red 
line), the output loss is less than half (about 0.4 percent lower GDP after 10 years of consecutive shocks).

Figure 2. Cumulated effects of average disaster shocks occurring every year in the Maldives

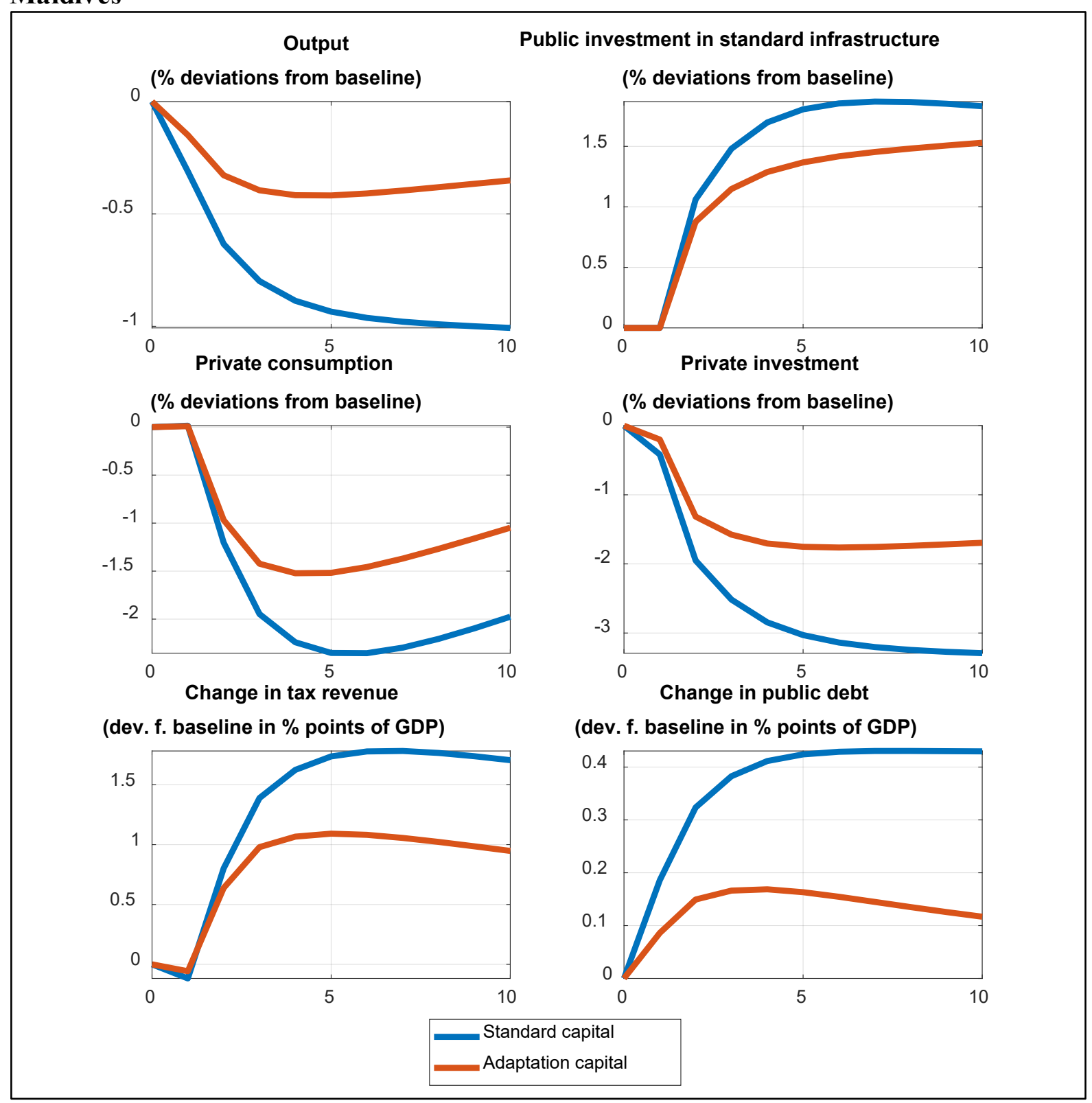

Note: Ba seline represents a scenario with the a bsence of disaster shocks.

It is noteworthy that the level of public investment necessary for the reconstruction after each natural disaster would have to be higher in the case of standard infrastructure. Therefore, after 10 years of consecutive shocks, the level of investment dedicated to replenish damaged capital (instead of creating new one) will be 2 percent higher than the baseline in the case of damages to standard infrastructure, while in the case of adaptation infrastructure it would be 1.5 percent higher than the baseline. Tax revenue to finance reconstruction in the case of 
standard infrastructure would have to be almost 2 percentage points of GDP higher than the baseline revenue after 10 years. In the case of infrastructure of better quality, the increase would have to be 1 percentage point of GDP higher than the baseline. Private consumption would also be facing a higher sacrifice in the case of an economy with standard capital, with losses that are double than those recorded in the case of an economy with adaptation capital.

\section{The gains from adaptation under worsened climate conditions}

In South Asia, rainfalls are expected to increase by 10-20 percent by the end of the $21^{\text {st }}$ century (IPCC, 2018). Natural disaster damages are therefore expected to become more severe going forward, and the gains from investing in adaptation infrastructure to be larger. To study this issue quantitatively, as in the exercise reported in Figure 2, we simulate a scenario in which the economy is hit annually by natural disaster shocks, but this time we increase the shock size by a factor equal to projected increases in rainfalls.

We report results for two alternative increases: (i) 15 percent, an intermediate value in the range of estimates; and (ii) 30 percent, a more severe increase that takes into account also phenomena not directly related to rainfall such as the sea-level rise and increased salinization, also expected to affect the Maldives in the future.

Figure 3 reports the cumulative output gains from investing in adaptation in frastructure under historical and worsened climate conditions. As in the experiment reported in Figure 2, we assume that the initial investment could be either for adaptation or standard infrastructure. At time 0 the investment project ends and, at time 1, the disaster shock sequence begins, as in Figure 2.

The blue line in Figure 3 plots the difference between the blue and the red line depicted in Figure 2, i.e. the cumulated impulse response functions of GDP in the case of adaptation infrastructure minus the same impulse response computed in the case of standard infrastructure (historical climate conditions). The red line represents the same difference calculated for the case of an alternative scenario where the shock size increases by 15 percent. Finally, the yellow line displays the same differences in GDP losses for shocks that are 30 percent worse.

Under historical climate conditions, captured by a sequence of shocks of size equal to the average of shocks recently observed in the Maldives, the output gain from investing in adaptation exceeds 0.6 percentage points over a ten-year horizon. Under worsened climate conditions, captured by an increase in the shock size, investing in adaptation infrastructure makes even greater economic sense because it reduces the extent of even larger damages. While an intermediate worsening in climate conditions (15 percent increase in the shock size) would increase the output gain from adaptation by 22 percent (to 0.8 percentage points), in even more severe climate scenarios (30 percent increase in the shock size) the increase in the output gain would double, reaching 0.94 percentage points. 
Figure 3. Cumulative output gains from investing in adaptation under historical and worsened climate conditions

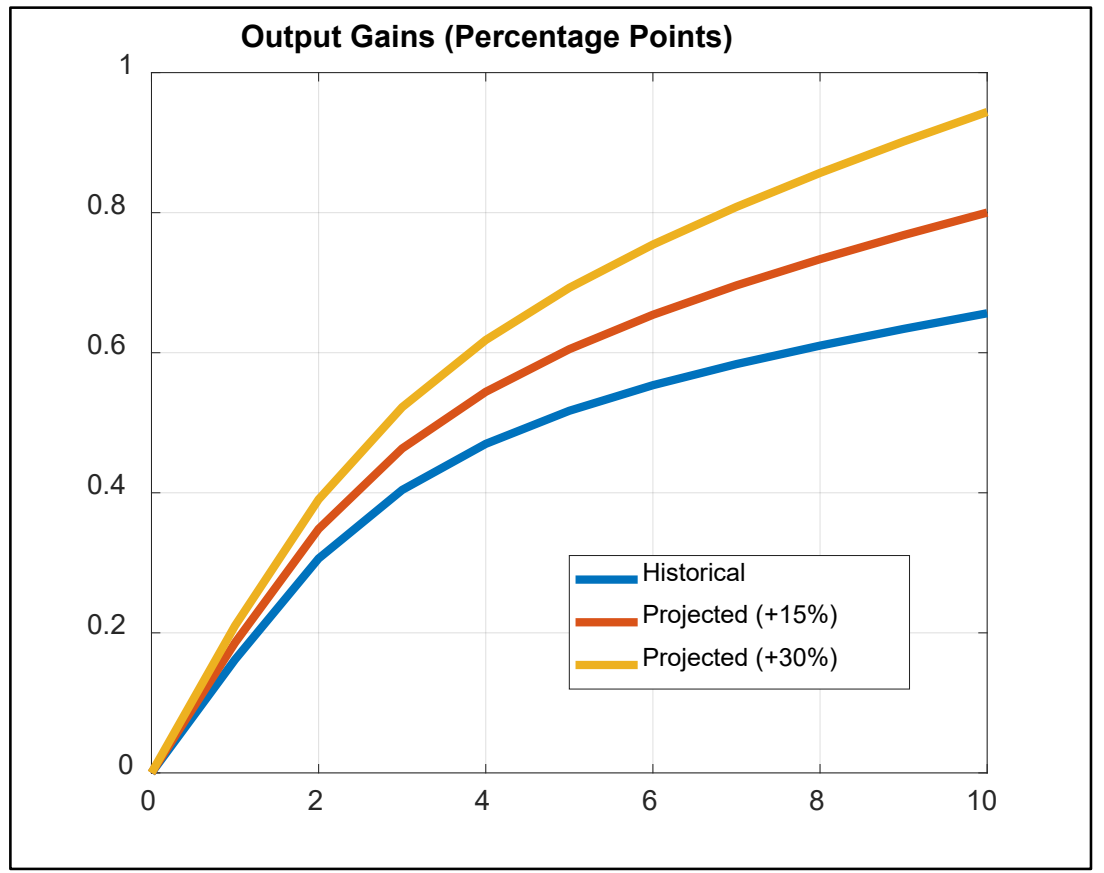

\section{Trade-offs for international donors}

As seen in the previous sections, the financial resources necessary to enhance preparedness for climate change in the Maldives could pose serious challenges. Donors might have to financially support the country during pre-disaster times, as well as in the midst of reconstruction phases, given the risk of unsustainable financial pressure, especially if the country is endowed solely with standard infrastructure.

The experiments described in this paper underscore the tradeoff faced by the international community: cooperating to financing the initial investment in adaptation infrastructure with prospects of much smaller post-disaster disbursements, or wait for the disaster to occur and sustain the cost of reconstruction in case of standard infrastructure, with potentially twice-aslarge disbursements. This trade-off is highlighted by the difference between the yellow and the blue line tracing the simulated dynamics of the tax revenue in Figure 1. This is also represented by the difference in the fiscal cost of public investment (in the aftermath of a disaster) in the case of standard versus adaptation infrastructure in Figure 2, right-top chart. To make things even more challenging, costs will be on a higher trajectory with climate conditions projected to worsen, as highlighted in the previous section.

The trade-off would have to take into account that, if donors decide to help build adaptation infrastructure, which will deliver much lower fiscal costs after a disaster shock, that initial investment would be more expensive than the cost of the same structures made of standard 
materials. Cantelmo, Melina and Papageorgiou (2019) report that the cost of resilient structures could be 25 percent higher than equivalent standard structures.

To better illustrate the trade-off faced by donors, we calculate the net present value of the costs associated with public investment for the reconstruction after natural disaster damages in the Maldives, in the case of both standard and adaptation infrastructure, under historical climate conditions. We compare the net savings arising from financing the extra initial cost to build adaptation infrastructure computed on a small investment envelope of half a percentage point of GDP.

In Table 2, column A, we report the net present value of the difference over ten years between the fiscal spending (public investment) for post-disaster reconstruction under the assumption that it is solely of the standard type (blue line in Figure 2, top-right chart) and the equivalent cost under the assumption that the infrastructure is of the resilient type (red line in Figure 2, top-right chart). We define this difference as the fiscal savings arising from the higher endurance to adverse climate events associated with adaptation infrastructure. The net present value of these savings is generated using different discount rates. In case of an intermediate value for the discount rate ( 3 percent), the ten-year saving could be as large as 18.7 million of 2019 USD. We then compare this value in column A with the extra spending associated to investing in adaptation infrastructure (column B), again discounted and evaluated at 2019 USD. This amounts to 7.9 million, with a net saving of almost 11 million USD. In other words, the cumulated discounted fiscal savings deriving from the smaller damages associated to adaptation infrastructure are more than double the size of the extra spending required to build it.

Table 2: Discounted ten-year gains and costs from investment in adaptation

\begin{tabular}{cccc}
\hline $\begin{array}{c}\text { Discount } \\
\text { rate }\end{array}$ & $\begin{array}{c}\text { Fiscal savings } \\
\text { (A) }\end{array}$ & $\begin{array}{c}\text { Extra spending } \\
\text { (B) }\end{array}$ & $\begin{array}{c}\text { Net savings } \\
(\mathbf{A})-(\mathbf{B})\end{array}$ \\
\hline & & & \\
$1 \%$ & 21.1 & 7.5 & 13.6 \\
$3 \%$ & 18.7 & 7.9 & 10.8 \\
$5 \%$ & 16.7 & 8.4 & 8.3 \\
& & & \\
\hline \multicolumn{2}{l}{ Note: All variables, except for the discount rate, are in millions of 2019 U.S. dollars. }
\end{tabular}

As discussed in the previous section, the projected worsening of precipitations and the increase in sea levels are likely to generate more frequent and/or more impactful disasters. Therefore, these calculations, based on historical climate conditions, represent a lower bound for future costs related to climate-related events. If climate conditions were to worsen, the estimates reported in Table 2 would point to even higher savings from building resilient infrastructure, making it more convenient for donors to contribute to the financing of resilience building before the realization of disasters. Furthermore, ex-ante donor support, tied to investment in resilience, carries also the potential benefit of reducing the scope for 
moral hazard problems, relative to ex-post intervention. In fact, countries may lack incentives to build resilience if they expect aid to be disbursed in the aftermath of a disaster.

\section{Conclusions}

In this paper, we employ a model, the Debt-Investment-Growth (DIG) of Buffie and others (2012), extended as in Marto, Papageorgiou, and Klyuev (2017) to make it suitable for small economies prone to natural disasters (DIGNAD), and calibrate it to the case of Maldives. We use the model to perform a series of stylized experiments and quantify the benefits of enhancing resilience in the Maldives.

We show that there is a dividend associated with building infrastructure using adaptation technologies. The initial cost of this type of infrastructure is usually elevated when compared to standard structures. However, when hit by a natural disaster shock, adaptation capital withstands adverse conditions reporting less damages, consequently cutting GDP losses by more than half. After showing the benefits associated with the adaptation infrastructure with a stylized experiment and one natural disaster shock, we analyze the case when an economy is hit by disasters of smaller magnitude but occurring periodically. These shocks are calibrated to an historic average size for floods that afflict the for the Maldives that about every year. We find that, in the long-run, the cumulated output loss suffered by the economy under the adaptation capital scenario is less than half the loss suffered under the standard capital scenario.

Finally, we also consider the case of worsening climate conditions, as projected in IPCC (2018). Under worsened climate conditions, the cumulative output gain from investing in adaptation increases up to a factor of two. Given the high fiscal costs associated with a strategy adequate to worsening climate conditions, the international community will likely have to step up cooperation efforts. We show that it is financially convenient for the international community to help small economies build resilience prior to the occurrence of natural disasters, rather than after the shocks materialize. International cooperation should also cover further capacity building in the area of public finance management, given the necessarily large investment associated with building resilience to natural disasters.

Although the qualitative implications of the results are robust within reasonable ranges of parameter values, the quantitative simulations rely on several parameters that have been set equal to cross-country averages, given limitations on Maldivian data. These include parameters related to the productivity of infrastructure investment and the resilience to natural disasters. In addition, similarly to all simulations related to climate change, our assumptions about worsened climate conditions (Section IV.C) are surrounded by significant uncertainty. Finally, simulations are constructed using illustrative scenarios of scale-ups in infrastructure spending. Results may be refined, as more data on authorities' infrastructure projects become available. 


\section{REFERENCES}

Agarwal, R., V. Balasundharam, P. Blagrave, E. Cerutti, R. Gudmundsson, and R. Mousa, 2021, Climate Change in South Asia: Further Need for Mitigation and Adaptation, IMF Working Paper, forthcoming.

Barro, R., 1990, "Government Spending in a Simple Model of Endogenous Growth,” Journal of Political Economy, Vol. 98(5), pp. S103-26.

Barro, R. and X. Sala-i-Martin, 1992, "Public Finance in Models of Economic Growth," Review of Economic Studies, Vol. 59(4), pp. 645-61.

Bayoumi T, S. N. Quayyum and S. Das, 2020, "Growth at Risk from Natural Disasters," IMF Working Paper, forthcoming, International Monetary Fund, Washington, DC.

Bevan, D. L. and S. J. Cook, 2015, "Public expenditure following disasters," Policy Research Working Paper Series 7355, The World Bank.

Buffie, E., Berg, A., Pattillo, C., Portillo, R., and L.F. Zanna, 2012, "Public Investment, Growth, and Debt Sustainability: Putting Together the Pieces," IMF Working Paper 12/144, International Monetary Fund, Washington, DC.

Canning, D., and E. Bennathan, 1999, "The Social Rate of Return on Infrastructure Investments," World Bank Policy Research Working Paper 2390, World Bank Group, Washington, DC.

Cantelmo A. L. Bonato, G. Melina and G. Salinas, 2019, "Policy Trade-offs in Buidling Resilience to Natural Disasters: The Case of St. Lucia", IMF Working Paper 19/54, International Monetary Fund, Washington, DC.

Cantelmo, A., Melina, G. and C. Papageorgiou, 2019, "Macroeconomic Outcomes in Disaster-Prone Countries”, IMF Working Paper 19/217, International Monetary Fund, Washington, DC.

Dalgaard, C. and H. Hansen, 2005, “The Return to Foreign Aid.” Discussion Paper No. 0504, Institute of Economics, University of Copenhagen.

Cavallo, E. and I. Noy, 2011, "Natural Disasters and the Economy-A Survey," International Review of Environmental and Resource Economics, vol. 5(1), pages 63-102, May.

Felbermayr, G. and J. Gröschl, 2014, "Naturally negative: The Growth Effects of Natural Disasters, Journal of Development Economics, 111, Issue C, p. 92-106.

Foster, V. and C. Briceo-Garmendia, 2010, Africa's Infrastructure: A Time for Transformation, forthcoming (Agence Française de Développement and the World Bank).

International Monetary Fund, [2020], Fiscal Policies To Address Climate Change In Asia And The Pacific, APD-FAD Departmental Paper, [December] (Washington: International Monetary Fund)

Intergovernmental Panel on Climate Change, 2018, “Global Warming of $1.5^{\circ} \mathrm{C}$ ”. IPCC Special Report.

Marto, R., Papageorgiou, C., and V. Klyuev, 2017, "Building Resilience to Natural Disasters: An Application to Small Developing States", IMF Working Paper 17/223,

International Monetary Fund, Washington, DC.

Noy, Ilan, 2009, "The macroeconomic consequences of disasters," Journal of Development Economics, Elsevier, vol. 88(2), pages 221-231, March.

Rozenberg, J., and M. Fay, 2019, Beyond the Gap: How Countries can Afford the Infrastructure They Need while Protecting the Planet, Sustainable Infrastructure (Washington: World Bank). 